\title{
TOLERÂNCIA DE FRUTOS DE PESSEGUEIRO A GEADAS ${ }^{1}$
}

\author{
ANDRÉ PAULO ASSMANN ${ }^{2}$, IDEMIR CITADIN ${ }^{3}$, \\ MAUROCRISTOVÃO LOCATELLI ${ }^{4}$, SILVIASCARIOT $^{4}$, \\ MOESES ANDRIGO DANNER ${ }^{5}$, MARIADO CARMO BASSOLS RASEIRA ${ }^{6}$
}

RESUMO - Este trabalho teve como objetivo avaliar a tolerância de frutos de pessegueiro aos danos ocasionados pela geada. A geada ocorreu no dia 5 de setembro de 2006 , sendo que a temperatura mínima, a $1,5 \mathrm{~m}$ do solo, foi de $-1,06^{\circ} \mathrm{C}$. Foram avaliados 28 genótipos de pessegueiro em diferentes estádios fenológicos. O delineamento experimental foi o inteiramente casualizado, com três repetições (plantas de pessegueiro), procedendo-se à avaliação em seis ramos por planta. No dia em que ocorreu a geada, foram mensurados o número de frutos por ramo, diâmetro sutural médio dos frutos, número total de gemas vegetativas, percentual de brotação e percentual de brindilas formadas a partir das gemas brotadas. Uma segunda avaliação foi realizada 15 dias após a primeira, para avaliar o percentual de queda de frutos e o diâmetro sutural médio dos frutos remanescentes. Genótipos bem enfolhados e cujos frutos apresentavam endocarpo endurecido, no momento da ocorrência da geada, foram tolerantes ao dano ocasionado pelo frio; frutos com diâmetro sutural inferior a $20 \mathrm{~mm}$ foram suscetíveis à geada, enquanto frutos com diâmetro sutural superior a 30 mm apresentaram boa tolerância, independentemente do genótipo avaliado.

Termos para Indexação: danos por congelamento, danos por frio, frutificação, Prunus persica.

\section{FRUIT FROST TOLERANCE IN PEACH}

ABSTRACT - The aim of this work was to evaluate the fruit damage tolerance in different peach tree genotypes after natural freeze. The frost happened on September 5, 2006, and the minimum temperature, 1.5 meters over soil, was $-1.06^{\circ} \mathrm{C}$. Twenty- eight peach tree genotypes, in different stages of development, were evaluated, in a completely random design, in three replication (plants) and six branches by plants. Immediately after frost, we measured the number of fruits per branches, average fruit suture diameter, percentage of sprouts and percentage of twigs in formation. A second evaluation was accomplished fifteen days after the first one in order to assess the percentage of fruit drop and the average remaining fruit suture diameter. Genotypes with good leafing and hard pit (endocarp) during frost have freeze tolerance; fruits with suture diameter lass than $20 \mathrm{~mm}$ are susceptible to frost damage, while fruits with suture diameter superior to $30 \mathrm{~mm}$ are tolerant.

Index terms: freeze injury, cold damage, fruit set, Prunus persica.

\section{INTRODUÇÃO}

No Brasil, a principal área produtora de pêssegos encontra-se localizada em latitudes superiores a $25^{\circ}$ sul, ou em alguns microclimas localizados abaixo dessa latitude, como na Serra da Mantiqueira, divisa entre os Estados de São Paulo, Minas Gerais e Rio de Janeiro. As condições climáticas dessas regiões são muito variáveis, principalmente no que se refere ao frio necessário para o desenvolvimento da cultura. Em geral, caracterizam-se por invernos amenos com grande oscilação de temperatura, típicas de clima subtropical. Também é freqüente a ocorrência de geadas tardias, principalmente nos meses de agosto e setembro, responsáveis pelo comprometimento parcial ou total da produção de algumas cultivares, cujas gemas floríferas ou frutos se encontram em estádios fenológicos de maior sensibilidade, no momento da ocorrência do fenômeno.

No Sul do Brasil, a ocorrência de geadas, em geral, coincide com o período de floração e desenvolvimento dos frutos (Raseira et al., 1992), constituindo um dos sérios problemas do cultivo do pessegueiro.

A resistência das estruturas reprodutivas do pessegueiro à geada é variável segundo a sua fase de desenvolvimento (Herter et al., 1998; Ballard et al., 1984, citado por Okie et al., 1998) e a cultivar utilizada (Cain et al., 1984; Byrne, 1986; Layne, 1989; Raseira et al., 1992). Alguns parâmetros foram associados à sobrevivência de estruturas reprodutivas do pessegueiro às geadas, tais como: tempo de floração prolongado (Scott \& Cullinan, 1939; Byrne, 1986), alta densidade de gemas (Byrne, 1986) e florescimento tardio (Byrne, 1986; Citadin et al., 2001), sendo que esses três parâmetros podem ser considerados na seleção de cultivares tolerantes às geadas. No entanto, a seleção de genótipos com florescimento tardio nem sempre é desejável em áreas onde a ênfase é o cultivo de material de frutificação precoce. Assim, o desafio do melhoramento é criar cultivares mais resistentes ou tolerantes às geadas tardias e que tenham maturação precoce.

Raseira et al. (1992) verificaram diferenças entre cultivares quanto à suscetibilidade ao frio na floração e sugerem a existência de um progenitor em comum entre as cultivares mais resistentes,

${ }^{1}$ (Trabalho 015-08). Recebido em:07-01-2008. Aceito para publicação em: 12-08-2008

${ }^{2}$ Acadêmico de Agronomia da UTFPR, Câmpus Pato Branco, Bolsista PIBIC-CNPq, andrebalisa@yahoo.com.br

${ }^{3}$ Engenheiro Agrônomo, Dr. em Agronomia, Professor UTFPR - Câmpus Pato Branco, idemir@utfpr.edu.br

${ }^{4}$ Acadêmicos de Agronomia da UTFPR, Câmpus Pato Branco, Estagiários em Fruticultura.

${ }^{5}$ Engenheiro Agrônomo, Mestrando em Agronomia, UTFPR - Câmpus Pato Branco, moesesandrigo@yahoo.com.br

${ }^{6}$ Engenheira Agrônoma, PhD em Melhoramento de Plantas, Embrapa Clima Temperado, bassols@cpact.embrapa.br

Rev. Bras. Frutic., Jaboticabal - SP, v. 30, n. 4, p. 1030-1035, Dezembro 2008 
e que esse caráter possua boa herdabilidade. Okie et al. (1998) verificaram diferentes intensidades de danos por geada, variando conforme a cultivar e local, sendo que a mesma cultivar, em diferentes locais, apresentou comportamento diferenciado, devido às diferenças climáticas (entre regiões), genéticas (entre as cultivares) e no estádio fenológico das cultivares no momento da geada.

O desenvolvimento de novas cultivares com flores e frutos resistentes às baixas temperaturas pode ajudar a resolver parcialmente o problema de danos pelo frio. A correta avaliação do grau de suscetibilidade dos frutos, em diferente estádio de desenvolvimento às geadas, poderá auxiliar nas práticas de manejo, visando a minimizar o problema. Por isso, o presente trabalho teve como objetivo avaliar a tolerância à geada em frutos de diferentes genótipos de pessegueiro, em diferentes estádios de desenvolvimento.

\section{MATERIAL E MÉTODOS}

As avaliações foram realizadas na coleção de genótipos de pessegueiro oriundas do programa de melhoramento da Embrapa Clima Temperado, Pelotas-RS, introduzidas na área experimental da Universidade Tecnológica Federal do Paraná (UTFPR), Câmpus Pato Branco-PR. O pomar experimental encontra-se localizado a $26^{\circ} 10^{\prime} \mathrm{S}, 52^{\circ} 41^{\prime} \mathrm{W}$ e $730 \mathrm{~m}$ de altitude. $\mathrm{O}$ clima no local é do tipo Cfb (Classificação de Köeppen), com média de 224 horas de frio abaixo de $7^{\circ} \mathrm{C}$ (maio a outubro) ou 166 horas (maio a julho), com amplitudes variando de 76 (1998) a 318 (2003) horas abaixo de $7^{\circ} \mathrm{C}$, segundo observações realizadas de 1979 a 2003 na área experimental do Instituto Agronômico do Paraná, em Pato Branco. A temperatura média das máximas é de $25,1^{\circ} \mathrm{C}$ e a média das mínimas de $14,3^{\circ} \mathrm{C}$. A temperatura mínima absoluta já registrada foi de $-4^{\circ} \mathrm{C}$ para o mês de julho, havendo a possibilidade de ocorrência de temperaturas negativas e geadas no mês de setembro (Wrege et al., 2004).

A geada ocorreu no dia 5 de setembro de 2006, sendo que a temperatura a $1,5 \mathrm{~m}$ do solo chegou a $-1,06^{\circ} \mathrm{C}$, às $6 \mathrm{~h} 30$. As temperaturas abaixo de zero grau iniciaram-se a partir das $4 \mathrm{~h} 30 \mathrm{e}$ perduraram até as $7 \mathrm{~h}$ (Figura 1 ).

Foram avaliados 28 genótipos de pessegueiro da coleção (Tabela 1), que se encontravam em diferentes estádios de desenvolvimento, imediatamente após a ocorrência da geada e 15 dias após o fenômeno. O delineamento experimental utilizado foi o inteiramente casualizado, com três repetições, compostas por uma planta, sendo que em cada planta foram avaliados seis ramos.

A coleção foi implantada em área de meia encosta, com exposição norte, e linhas direcionadas no sentido leste-oeste, de acordo com as curvas de nível. As plantas foram conduzidas em sistema de vaso, com espaçamento de $4 \mathrm{~m} \times 5 \mathrm{~m}$ entre plantas e linhas, respectivamente. As podas foram realizadas de acordo com as recomendações gerais para a cultura. Nas entrelinhas, foi mantida a cobertura de solo com trevo-branco (Trifolium repens) e plantas voluntárias, manejadas através de roçadas, e o controle de plantas daninhas nas linhas, através de capinas. As demais práticas, tais como adubação, raleio, tratamento de inverno e controle de pragas e doenças, foram realizadas conforme recomendações gerais para a cultura. Não foi utilizada a quebra de dormência com o do uso de produtos químicos.

No dia da ocorrência da geada, mensuraram-se o número de frutos por ramo, o diâmetro sutural médio (DSM) dos frutos (maior diâmetro perpendicular ao eixo do fruto), percentual de brotação e percentual de brindilas em formação, em relação ao número de gemas brotadas. Quinze dias após, avaliaram-se o número de frutos remanescentes e o diâmetro sutural médio dos mesmos. A partir dos dados obtidos, foram calculados os percentuais de queda de frutos provocada pela geada, de brotação e de brindilas em formação.

Os resultados foram submetidos à análise de variância, sendo que, para as variáveis expressas em percentual, os dados foram transformados pela arco-seno $\sqrt{x / 100}$,e as médias, comparadas pelo teste de Scott-Knott $(P \leq 0,05)$. Foram realizadas análises de correlação linear pelo método de Pearson, com auxílio do programa computacional 'Genes' (Cruz, 2001), para as correlações que se mostraram significativas pelo teste $\mathrm{t}(P \leq 0,01)$.

\section{RESULTADOS E DISCUSSÃO}

Os genótipos diferiram, apresentando-se como mais tolerantes à geada, as cultivares Bonão, Tropic Beauty e Atenas, e as seleções Cascata 962, Conserva 1187, Conserva 985, Conserva 1125 e Cascata 1063, com percentuais de queda de frutos menores que 21\% (Tabela 1). Já os genótipos Conserva 871, Conserva 1070, Cascata1065 e Conserva 681 tiveram sua produção completamente comprometida pela geada (Tabela 1), não diferindo da cultivar Tropic Snow e das seleções Cascata 1055, Conserva 1129 e Conserva 1205.

Os frutos danificados pela geada apresentaram lesões no epicarpo e na amêndoa, com paralisação do crescimento e subseqüiente abscisão dos frutos. Sintomas semelhantes foram descritos por Herrerro et al. (2006) em frutos de damasqueiro.

Observou-se correlação negativa e significativa $(\mathrm{r}=-0,74 * *)$ entre o diâmetro sutural dos frutos, no momento da ocorrência da geada, e o percentual de queda desses, sendo que, em geral, quanto maior o diâmetro, menor foi o dano ocasionado pela geada (Figura 2A). Assim, os frutos foram classificados em três classes distintas quanto aos danos provocados pela geada: resistentes (> $30 \mathrm{~mm})$, comportamento variável $(20$ a $30 \mathrm{~mm})$ e suscetíveis $(<20 \mathrm{~mm})$.

Em geral, os genótipos que apresentavam frutos com diâmetro inferior a $20 \mathrm{~mm}$ no momento da ocorrência da geada, sofreram dano superior a $85 \%$ (Tabela 1). Entretanto, o genótipo Cascata 1065, que teve toda a sua produção comprometida pela geada, apresentava diâmetro sutural médio de fruto de $22,35 \mathrm{~mm}$. Pode-se, assim, dizer que a ocorrência de geadas antes do endurecimento do caroço compromete a produção, como ocorrido com o genótipo Cascata 1065, sendo que, quando esse fenômeno ocorre no final de floração ou início da formação (fixação) dos frutos (Cons. 681), os danos são ainda mais expressivos, ocorrendo perda total da produção. Essa hipótese pode ser corroborada pela observação da correlação positiva e significativa $(\mathrm{r}=0,74 * *)$ entre o diâmetro sutural médio (DSM) 
dos frutos, quinze dias após a primeira mensuração (Figura 2B), e o percentual de fixação de frutos. Neste caso, todos os frutos que permaneceram nas plantas, apresentavam DSM superior a $20 \mathrm{~mm}$, sendo que a grande maioria possuía DSM maior que 30 $\mathrm{mm}$.

O crescimento e o desenvolvimento dos frutos de pessegueiro, que seguem o padrão de curva sigmoidal-dupla, apresentam três estádios distintos. No estádio I, as concentrações dos fitormônios permanecem em níveis semelhantes; no estádio II, eleva-se a concentração de AIA (ácido-indolacético), ocorrendo as maiores e mais importantes mudanças fisiológicas e anatômicas do fruto, tais como a diminuição do ritmo de crescimento da polpa, endurecimento do caroço e formação parcial da semente. No estádio III, há redução na concentração de AIA na semente,e a polpa retoma seu crescimento, aumentando o volume celular e espaços intracelulares, havendo um rápido crescimento da polpa (Valio, 1985; Miller et al., 1987; Barbosa et al., 1990; Chitarra \& Chitarra, 1990).

Segundo Barbosa et al. (1993), o endurecimento do caroço (estádio II) ocorre quando os frutos atingem de 15 a $20 \mathrm{~mm}$ de diâmetro, correspondente a frutos com 5 a 15 gramas, dependendo do grau de precocidade da maturação de cada genótipo. O mesmo autor verificou diferenças na duração dos estádios de acordo com o grau de precocidade dos materiais, sendo que, para a duração dos estádios I e II, há poucas diferenças entre materiais de ciclo médio e tardio. Entretanto, Pereira et al. (1987) verificaram variação mais pronunciada na duração do estádio II, o qual foi mais curto para a cultivar precoce, aumentando com o atraso na maturação. Em geral, o estádio II acontece entre o $36^{\circ}$ e $49^{\circ}$ dia após a antese. Geralmente, em cultivares precoces, há um adiantamento desse estádio em relação às cultivares tardias.

Os genótipos cujos frutos apresentavam, no dia da ocorrência da geada, menos que 36 dias da plena floração, foram severamente danificados. Esses genótipos apresentavam menor diâmetro de frutos (Tabela 1). Assim, verificou-se correlação negativa e significativa $\left(\mathrm{r}=-0,63^{* *}\right)$ entre o tempo decorrido da plena floração à ocorrência da geada e o percentual de abscisão de frutos (Figura 2E).

Observa-se que o diâmetro do fruto, bem como o tempo entre a plena floração até a ocorrência da geada, está ligado ao processo de endurecimento do endocarpo (caroço), e esse fator condiciona maior resistência aos danos ocasionados pelo frio. Nesse sentido, podem-se dimensionar as práticas de prevenção à geada de acordo com o estádio de desenvolvimento dos frutos, sendo que medidas mais cuidadosas devem ser tomadas da floração ao endurecimento do endocarpo e mais amenas após o endurecimento desse. Segundo Pereira et al. (1987), o início da fase de endurecimento do endocarpo é caracterizado pela mudança de coloração da sua extremidade, passando de branco para amarelo-creme, apresentando resistência ao corte, conforme o endurecimento progride, até o ponto no qual se encontra suficientemente duro para não permitir seu corte em fatias finas.

Os genótipos com diâmetro de frutos entre 20 e $30 \mathrm{~mm}$ apresentaram comportamento variado quanto à relação tamanho de fruto e percentual de queda, variando de 4 a $84 \%$ de dano (Tabela 1), com tendência a aproximar-se do limite superior ou inferior, conforme diminuía ou aumentava, respectivamente, o tamanho dos frutos. Esse comportamento variado pode estar associado às diferenças nos ciclos dos materiais e ao padrão de desenvolvimento do fruto. Assim, em alguns genótipos, o endurecimento do endocarpo pode ocorrer com diâmetros menores ou maiores, dependendo do tamanho final dos frutos e do período decorrido da floração à colheita.

Genótipos com DSM igual ou superior a $30 \mathrm{~mm}$ tiveram percentuais de queda de frutos próximos ou inferiores a $20 \%$, exceto o genótipo Conserva 688 (DSM 30,07 mm) com 40\% de perda. Esse genótipo apresentava baixo percentual de brotação e de brindilas em formação no momento da ocorrência da geada, o que pode ter contribuído para a intensificação do dano. Observou-se correlação negativa e significativa $(\mathrm{r}=-0,64 * *)$ entre o percentual de brotação de gemas e o percentual de queda de frutos (Figura 2C), indicando que materiais bem enfolhados no momento da geada são menos propensos à queda de frutos ocasionados pelo frio intenso. No entanto, também se verificou que, até genótipos com altos percentuais de brotação e tamanho de fruto próximo de $30 \mathrm{~mm}$ apresentaram danos severos à geada, revelando correlação com a qualidade da brotação desenvolvida. Assim, houve correlação negativa e significativa $(r=-0,62 * *)$ entre o percentual de brindilas desenvolvidas a partir da brotação e a queda de frutos ocasionada pela geada (Figura 2D), ou seja, quanto maior o percentual de brindilas em formação, menor o dano de geadas. O percentual de brotação está relacionado com a necessidade de frio de cada genótipo (Weinberger, 1950; Richardson et al., 1974; Scorza \& Sherman, 1996; Citadin et al., 2002). Genótipos que não tenham atendido totalmente à necessidade de frio, apresentando baixa brotação ou, quando brotam, não desenvolvem brindilas, formando estruturas conhecidas como rosetas, que caracterizam uma planta pouco enfolhada.

O genótipo Tropic Snow, com diâmetro de frutos próximo a $30 \mathrm{~mm}$ e alto percentual de brotação, apresentou percentual de dano de 83,33\% (Tabela 1). Observou-se, no momento da ocorrência da geada, que essa cultivar apresentava apenas 6,02\% de brindilas em formação, caracterizando, no momento da ocorrência da geada, baixo enfolhamento, não proporcionando adequada proteção ao fruto. Foi verificado, visualmente no experimento, que frutos que se encontravam protegidos pelas folhas, foram menos propensos aos efeitos da geada. Constatouse também que, em genótipos que apresentaram brotação tardia, os percentuais de danos à geada foram maiores em relação aos de brotação precoce, conforme observado nos genótipos Conserva 977, Tropic Snow, Conserva 655, Conserva 985, Cascata 1055 e Conserva 1129.

No genótipo Conserva 1129, observaram-se visualmente, no momento da colheita, seqüelas ocasionadas pelos danos de geadas em frutos que resistiram à abscisão. Nos frutos danificados pelo congelamento, houve paralisação do crescimento na parte afetada, causando deformações, redução de tamanho e antecipação da maturação.

Embora tenham sido evidenciadas diferenças entre os genótipos avaliados quanto à tolerância à geada, não se pode afirmar que essa característica seja de efeito genético. Entretanto, 
verificou-se claramente a influência do estádio do desenvolvimento do fruto e do grau de enfolhamento dos genótipos como fatores reguladores dessa tolerância. Assim, genótipos de florescimento e brotação precoces podem apresentar produtividades satisfatórias, mesmo em anos de ocorrência de geada tardia, desde que esse fenômeno não ocorra em intensidades menores que $-1^{\circ} \mathrm{C}$ e que esses genótipos estejam bem enfolhados e com frutos com o endocarpo endurecido, condições que permitem a minimização dos danos. Por outro lado, genótipos de florescimento e brotação tardias podem apresentar maior suscetibilidade aos danos causados pelo frio que genótipos precoces, dependendo da condição da planta e do fruto no momento da ocorrência da geada. Nesse sentido, devem-se adotar práticas diferenciadas de prevenção à geada, dependendo da fase de desenvolvimento da planta.

TABELA 1- Percentuais de queda de frutos 15 dias após a ocorrência da geada; percentual de brotação, percentual de brindilas, diâmetro sutural médio do fruto (DSM) no dia da ocorrência da geada; dias decorridos entre a plena floração e a data de ocorrência da geada e ciclo (da plena floração à colheita) de genótipos de pessegueiro. UTFPR, Câmpus Pato Branco, 2006.

\begin{tabular}{|c|c|c|c|c|c|c|}
\hline Genótipo & $\%$ queda & \% brotação & $\%$ brindilas & DSM (mm) & Dias da plena floração à & Ciclo (dias) \\
\hline Bonão & 3,03 & 83,18 a & $34,31 \quad \mathrm{a}$ & $49,78 \mathrm{a}$ & 75 & 107 \\
\hline Tropic Beauty & 4,17 & 85,19 a & $24,04 \mathrm{~b}$ & $28,85 \mathrm{~b}$ & 68 & 104 \\
\hline Casc. 962 & 7,02 & 93,24 a & 34,04 a & $28,92 \mathrm{~b}$ & 64 & 98 \\
\hline Cons. 1187 & 7,50 & 77,93 a & $26,96 \mathrm{~b}$ & $25,44 \mathrm{~b}$ & 61 & 96 \\
\hline Cons. 985 & $9,52 \mathrm{~d}$ & $60,02 \mathrm{~b}$ & $10,35 \mathrm{c}$ & $31,77 \mathrm{~b}$ & 43 & 120 \\
\hline Atenas & $12,80 \mathrm{~d}$ & 90,52 a & 36,42 a & $28,04 \mathrm{~b}$ & 61 & 127 \\
\hline Cons. 1125 & $15,28 \mathrm{~d}$ & 90,95 a & 50,10 a & $34,15 \mathrm{~b}$ & 67 & 100 \\
\hline Casc. 1063 & $20,21 \mathrm{~d}$ & 88,52 a & $28,66 \mathrm{~b}$ & $33,01 \mathrm{~b}$ & 61 & 103 \\
\hline Cons. 1153 & $26,87 \mathrm{c}$ & 77,46 a & 43,10 a & $28,47 \mathrm{~b}$ & 73 & nd \\
\hline Cons. 844 & $36,67 \mathrm{c}$ & 82,66 a & $21,31 \mathrm{~b}$ & $28,90 \mathrm{~b}$ & 61 & 96 \\
\hline Cons. 688 & $39,96 \mathrm{c}$ & $60,75 \mathrm{~b}$ & 43,83 a & $30,37 \mathrm{~b}$ & 57 & 146 \\
\hline Cons. 803 & $48,33 \mathrm{c}$ & 88,97 a & 40,52 a & $24,67 \mathrm{~b}$ & 42 & 114 \\
\hline Cons. 1223 & $48,69 \mathrm{c}$ & 86,16 a & 33,05 a & $25,62 \mathrm{~b}$ & 45 & 93 \\
\hline Cons. 1127 & $57,74 \mathrm{~b}$ & 85,14 a & 37,38 a & $25,73 \mathrm{~b}$ & 68 & nd \\
\hline Casc. 834 & $59,44 \mathrm{~b}$ & 90,28 a & 43,68 a & $26,63 \mathrm{~b}$ & 61 & nd \\
\hline Cons. 977 & $65,54 \mathrm{~b}$ & 70,85 a & $20,24 \mathrm{~b}$ & $26,13 \mathrm{~b}$ & 67 & 146 \\
\hline Cons. 655 & $69,05 \mathrm{~b}$ & $69,47 \mathrm{~b}$ & $23,78 \mathrm{~b}$ & $24,20 \mathrm{~b}$ & 49 & 138 \\
\hline Olímpia & $69,93 \mathrm{~b}$ & 78,46 a & $21,24 \mathrm{~b}$ & $25,68 \mathrm{~b}$ & 56 & 184 \\
\hline Rubimel & $74,75 \mathrm{~b}$ & 73,87 a & $25,11 \mathrm{~b}$ & $25,31 \mathrm{~b}$ & 66 & 114 \\
\hline Cons. 1186 & $77,50 \mathrm{~b}$ & $60,93 \mathrm{~b}$ & $20,59 \mathrm{~b}$ & $26,13 \mathrm{~b}$ & 42 & 90 \\
\hline Cons. 1205 & 81,11 a & $50,62 \mathrm{~b}$ & 32,84 a & $25,08 \mathrm{~b}$ & 52 & 152 \\
\hline Tropic Snow & 83,33 a & 89,02 a & $6,02 \mathrm{c}$ & $29,22 \mathrm{~b}$ & 75 & 117 \\
\hline Cons. 1129 & 85,74 a & $41,91 \mathrm{~b}$ & 8,81 & $16,99 \mathrm{c}$ & 42 & 84 \\
\hline Casc. 1055 & 89,81 a & $62,48 \quad b$ & 0,93 & $14,86 \mathrm{c}$ & 31 & 80 \\
\hline Cons. 871 & $100,00 \mathrm{a}$ & $63,65 \mathrm{~b}$ & 7,72 & $11,63 \mathrm{c}$ & 26 & nd \\
\hline Casc. 1070 & $100,00 \mathrm{a}$ & $48,19 \mathrm{~b}$ & 5,32 & $16,68 \mathrm{c}$ & 26 & nd \\
\hline Casc. 1065 & $100,00 \mathrm{a}$ & $43,74 \mathrm{~b}$ & 3,85 & $22,35 \mathrm{~b}$ & 35 & nd \\
\hline Cons. 681 & $100,00 \mathrm{a}$ & $57,61 \mathrm{~b}$ & 0,00 & $8,55 \mathrm{c}$ & 26 & nd \\
\hline Média & 53,36 & 73,28 & 24,43 & 25,83 & - & - \\
\hline Desvio Padrão & 16,58 & 12,53 & 6,23 & 4,92 & - & - \\
\hline CV (\%) & 31,08 & 17,11 & 25,52 & 19,06 & - & - \\
\hline
\end{tabular}

*Médias seguidas de mesma letra não diferem entre si, pelo teste de Scott-Knott $(P \leq 0,05)$.nd - não-determinado.

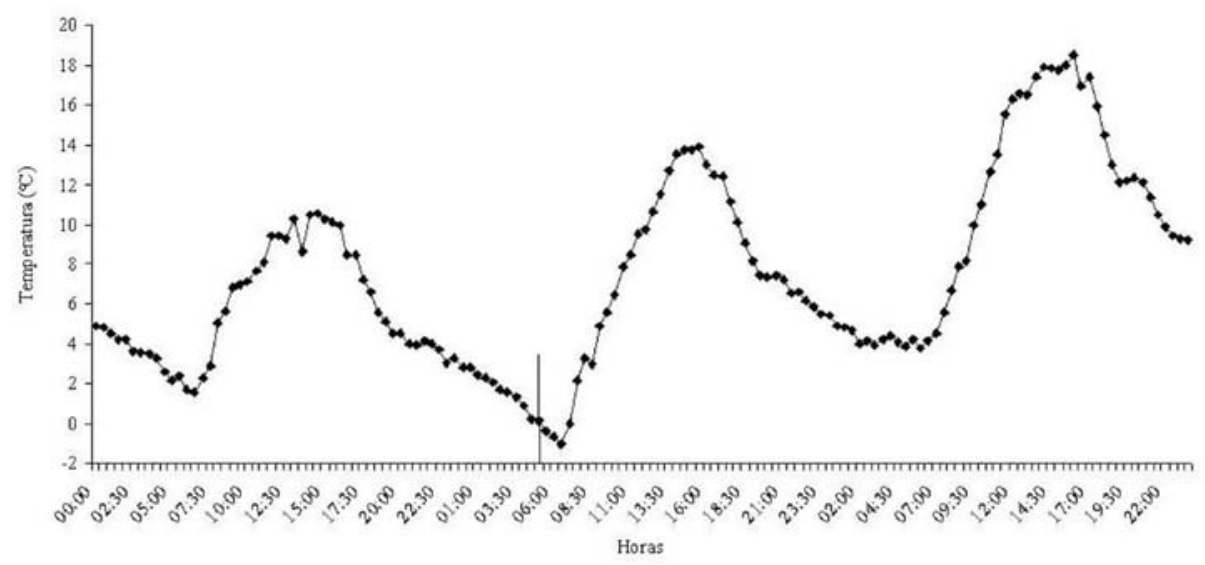

FIGURA 1 - Variação diária da temperatura do ar para os dias 4, 5 e 6 de setembro de 2006. A linha indica o início da ocorrência da geada. UTFPR, Câmpus Pato Branco, 2006. 
A

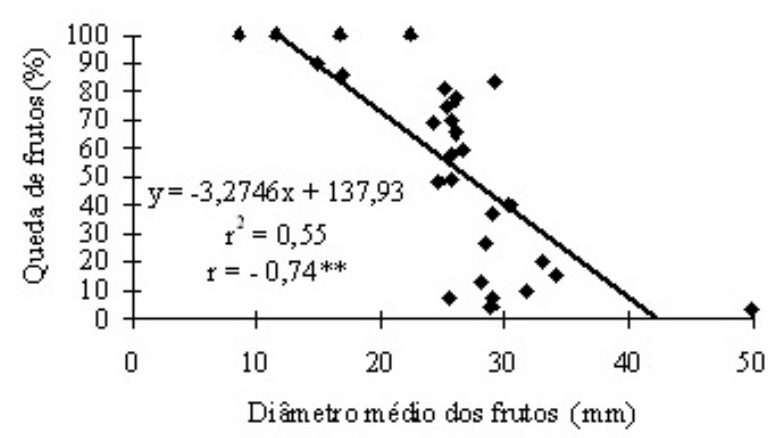

C

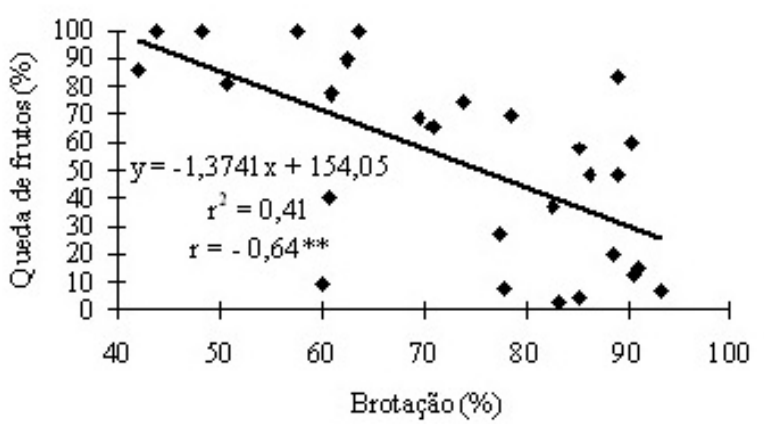

$\mathbf{E}$

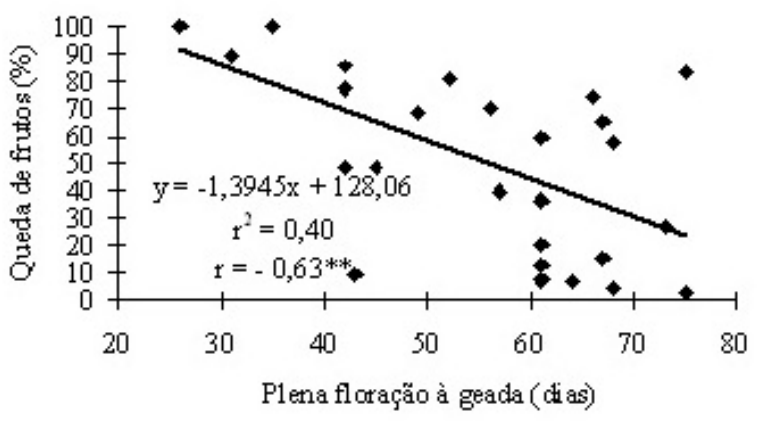

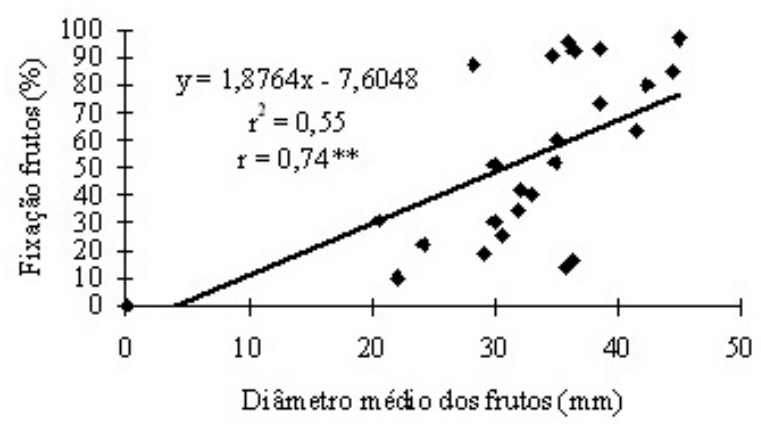

D

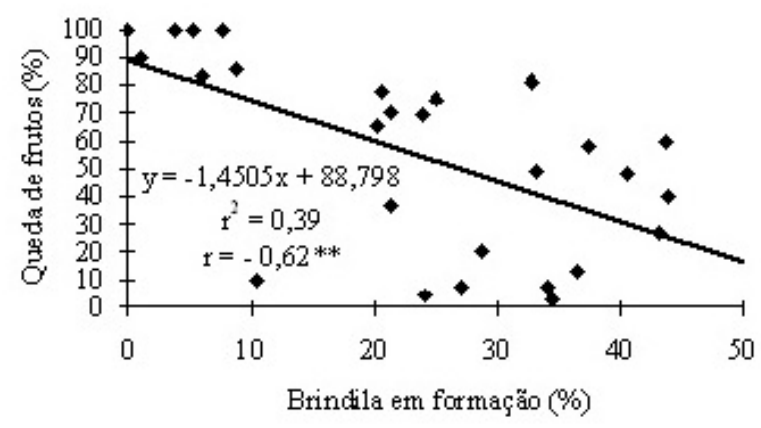

FIGURA 2- Correlação entre queda de frutos e diâmetro médio de frutos no dia da ocorrência da geada (A); fixação de frutos e diâmetro médio de frutos 15 dias após a ocorrência da geada (B) ; queda de frutos e percentual de brotação (C); queda de frutos e percentual de brindila em formação (D) e queda de frutos e dias decorridos da plena floração à

geada (E). UTFPR - Câmpus Pato Branco, 2006.

\section{CONCLUSÕES}

1-Genótipos bem enfolhados e cujos frutos apresentam endocarpo endurecido, no momento da ocorrência da geada, foram mais tolerantes ao dano ocasionado pela geada.

2-Frutos com diâmetro sutural inferior a $20 \mathrm{~mm}$ foram suscetíveis aos danos de geadas, enquanto frutos com diâmetro sutural superior a $30 \mathrm{~mm}$ apresentaram boa tolerância.

\section{AGRADECIMENTOS}

Ao CNPq, pela concessão da Bolsa de Iniciação Científica, e à Embrapa Clima Temperado, por disponibilizar os genótipos para a composição da coleção. 


\section{REFERÊNCIAS}

BARBOSA, W.; DALL'ORTO, F.A.C.; OJIMA, M.; SAMPAIO, V.R.; BANDEL, G. Ecofisiologia do desenvolvimento vegetativo e reprodutivo do pessegueiro em região subtropical. Campinas: Instituto Agronômico, 1990. (Documentos, IAC 17).

BARBOSA, W.; OJIMA, M.; DALL'ORTO, F.A.C.; MARTINS, F.P.; LOVATE, A.A. Desenvolvimento dos frutos e das sementes de pêssegos subtropicais de diferentes ciclos de maturação. Pesquisa Agropecuária Brasileira, Brasília, v.28, n.6, p.701-707, 1993.

BYRNE, D.H. Mechanisms of spring freeze injury avoidance in peach. HortSience, Alexandria, v.21, n.5, p.1235-1236, 1986.

CAIN, W.D.; RIDLEY, J.D.; NEWALL, W.C. Fruit survival of peach and nectarines fallowing late spring two years. Fruit Varieties Journal, Urbana, v.38, n. 4, p. 136-139, 1984.

CHITARRA, M.I.F.; CHITARRA, A.B. Pós-colheita de frutas e hortaliças: fisiologia e manuseio. Lavras: ESAL; FAEPE, 1990. $320 \mathrm{p}$.

CITADIN, I.; RASEIRA, M.C.B.; HERTER, F.G.; SILVA, J.B. Heat requirement for blooming and leafing in peach. HortScience, Alexandria, v.3, n.2, p.305-307, 2001.

CITADIN, I.; RASEIRA, M.C.B.; HERTER, F.G.; SILVEIRA, C.A.P. Avaliação da necessidade de frio em pessegueiro. Revista Brasileira de Fruticultura, Jaboticabal, v.24, n.3, p.703-706, 2002.

CRUZ, C.D. Programa Genes: versão Windows: aplicativo computacional em genética e estatística. Viçosa: UFV, 2001. 648p.

HERRERO, M.; RODRIGO, J.; JULIAN C. Springs frost damage in buds, flower and developing fruits in apricot. Acta Horticulturae, Wageningen, p. 87-88, 2006.

HERTER, F.G.; SACHS, S.; FLORES, C.A. Condições Edafoclimáticas para a instalação do pomar In: MEDEIROS, C.A.B.; RASEIRA, M.C.B. A cultura do pessegueiro. Brasília: Embrapa-SPI; Pelotas: Embrapa-CPACT, 1998, p.20-27.

LAYNE, R.E.C. Breeding cold hardy peach cultivars for Canada. Acta Horticulturae, Wageningen, v.254, p.73-78, 1989.
MILLER, A.N.; WALSH, C.S.; COHEN J.D. Measurement of indole-3-acetic acid in peach fruits (Prunus persica $\mathrm{L}$. Batsch cv. Redhaven) during development. Plant Physiology, Rockville, v. 84, n. 3, p. 491-494, 1987.

OKIE, W.R.; REIGHARD, G.L.; NEWALL, JR., W.C.; GRAHAM, C.J.;WERNER, D.J.; POWEL, A.; KREWER, G.; BECKMAN, T.G. Spring freeze damage to the 1996 peach and nectarine crop in the Southeastern United States. HortTechnology, Alexandria, v.8, n.3, p.381-386, 1998.

PEREIRA, J.F.M.; FELICIANO, A.J.; RASEIRA, M.C.B.; SILVA, J.B. Curvas de crescimento, épocas de raleio e previsão do tamanho final do fruto em três cultivares de pessegueiro. Pesquisa Agropecuária Brasileira, Brasília, v.22, n.9-10, p.965-974, 1987.

RASEIRA, M.C.B.; BAPTISTA, J.S.; HERTER, F.G.; PETERS, J.A. Sensibilidade de gemas floríferas de pessegueiro, Prunus persica L. Batsch, ao frio. Revista Brasileira de Fruticultura, Jaboticabal, v.14, n.1, p.167-172, 1992.

RICHARDSON, E.A.; SEELEY, S.D.; WALKER, D.R. A model for estimating the completion of rest of 'Redhaven' an 'Elberta' peach trees. HortScience, Alexandria, v.9, p.331-332, 1974.

SCORZA, R.; SHERMAN, W.B. Peaches. In: JANICK, J.; MOORE, J.N. Fruit breeding: tree and tropical fruits. New York: John Wiley \& Sons, 1996. v.1, p.325-440.

SCOTT, D.H.; CULLIAN, F.P. Peach variety resistance to cold injury at blossom time. Journal American Society Horticulture Science, Mount Vernon, v.37, p.209-214, 1939.

VALIO, I.F.M. Frutificação. In: FERRI, M.G. Fisiologia vegetal. São Paulo: EPU, 1985. v.2, p.313-342.

WEINBERGER, J.H. Chilling requirements of peach varieties. Proceedings of the American Society for Horticultural Science, Mount Vernon, v.56, p.122-128, 1950.

WREGE, M.S.; CARAMORI, P.H.; GONÇALVES, A.C.A. ; BERTONHA, A.; CAVIGLIONE, J.H.; FARIA, R.T.; FREITAS, P.S.L.; GONÇALVES, S.L. Ocorrência da primeira geada de outono e última de Primavera no Estado do Paraná. Revista Brasileira de Agrometeorologia, Santa Maria, v.12, n.1, p.143-150, 2004. 